\title{
SEVERE CEREBRAL AND CARDIAC DYSFUNCTION ASSOCIATED WITH THYROID DECOMPENSATION AFTER CARDIAC OPERATIONS
}

\author{
Jehangir J. Appoo, BSc, and Jean Francois Morin, MD, FRCSC, Montreal, Quebec, Canada
}

Cerebral and cardiac dysfunctions are common complications of cardiac operations. The widely known causes include cerebral hypoperfusion, embolism, and inadequate myocardial protection. Severe hypothyroidism causing myxedema coma and cardiac depression after cardiac operations is rare but should be considered, because cardiac surgery can aggravate hypothyroidism, and the complications are reversible with prompt recognition and appropriate therapy.

Clinical summary. A 78-year-old man was brought to The Montreal General Hospital with acute pulmonary edema. Cardiac catheterization showed grade III-IV mitral regurgitation, two-vessel coronary artery disease, and a left ventricular ejection fraction of $60 \%$. The patient was taken to the operating room, where an uneventful mitral valve repair and double aorta-coronary bypass were performed.

Two hours after arrival in the surgical intensive care unit, the patient began having generalized tonic clonic seizures. An electroencephalogram showed diffuse and persistent dysfunction of cerebral activity, and a regimen of anticonvulsants was begun. A computed tomographic scan of the head was interpreted as showing no abnormalities. Over the next 2 days the seizures stopped and the anticonvulsants were discontinued, but the patient remained comatose. The cardiovascular status worsened. On postoperative day (POD) 3 the patient had a low cardiac output necessitating inotropic drugs, had severe bradycardia, and was pacemaker dependent. The electrocardiogram showed low voltages. An increased cardiac size was noted on a chest x-ray film. An echocardiogram showed a decreased left ventricular ejection fraction, akinesis of the inferior wall, and severe hypokinesis of the remaining walls. The patient had remained hypothermic (core temperature $35.3^{\circ} \mathrm{C}$ to $37.0^{\circ} \mathrm{C}$ ) since arriving in the intensive care unit, despite the use of a heating blanket.

At this point, a review of the patient's file showed that thyroid function tests had been ordered a week before the operation. The patient had an elevated thyroid-stimulating hormone level of $25.3 \mathrm{mU} / \mathrm{L}$ (normal range 0.5 to 4.0 $\mathrm{mU} / \mathrm{L}$ ) and a low free thyroxine level of $7.8 \mathrm{pmol} / \mathrm{L}$ (normal range 10 to $23 \mathrm{pmol} / \mathrm{L}$ ) at the time. Thyroid

From the Division of Cardiothoracic Surgery, The Montreal General Hospital, McGill University, Montreal, Quebec, Canada.

Received for publication Feb. 11, 1997; accepted for publication March 19, 1997.

Address for reprints: Jean F. Morin, MD, FRCSC, Room L9-113, The Montreal General Hospital, 1650 Cedar Ave., Montreal, PQ, Canada H3G $1 \mathrm{~A} 4$.

J Thorac Cardiovasc Surg 1997;114:496

Copyright $\odot 1997$ by Mosby-Year Book, Inc.

$0022-5223 / 97 \$ 5.00+0 \quad \mathbf{1 2 / 5 4 / 8 2 0 9 6}$ function tests were immediately repeated on POD 3 . The free thyroxine level was $6.6 \mathrm{pmol} / \mathrm{L}$ and the thyroidstimulating hormone level was $13.7 \mathrm{mU} / \mathrm{L}$. The patient was started on a program of oral levothyroxine sodium.

On POD 4 the patient remained comatose. That night an extra dose of levothyroxine was given intravenously. The next morning (POD 5) the patient was able to open his eyes spontaneously on command. Oral levothyroxine was stopped and the patient was switched to parenteral levothyroxine. By POD 6 the patient was alert with impaired but improving motor function in the upper and lower extremities. He was no longer receiving inotropic drugs, and a second echocardiogram showed improved biventricular systolic function. On POD 8 the patient was extubated. During the first 9 PODs the patient remained slightly hyponatremic. The rest of the electrolyte and glucose levels remained within normal ranges. Repeated electroencephalograms showed no potential epileptiform activity.

On discharge to his home (POD 20) the patient was feeling well and ambulating. Follow-up 6 months after discharge revealed that the thyroid condition was well controlled with oral levothyroxine. Results of an antithyroid microsomal antibody test done at this time were positive, suggesting an underlying chronic immune thyroiditis.

Discussion. Central nervous system dysfunction after cardiac operations is a common complication that is usually attributed to the effects of cardiopulmonary bypass on the brain. ${ }^{1}$ Thus, when a patient has complications related to the central nervous system after a cardiac operation, other possible causes are rarely considered.

This patient's hypothyroidism, documented before the operation, was likely to have been further exacerbated by cardiopulmonary bypass, inasmuch as the latter has been shown to decrease circulating levels of free triiodothyronine and increase levels of reverse triiodothyronine (biologically inactive form of thyroid hormone), ${ }^{2}$ a state known as the sick euthyroid syndrome. In a literature review, only one other case of postoperative myxedema coma was found to have been reported in the past 10 years. $^{3}$

In summary, a hypothyroidal state after a cardiac operation may cause defective thermoregulation, heart failure, coma, and death. If the diagnosis of hypothyroidism is entertained and treated properly, these conditions are all reversible and the patient can be saved.

\section{REFERENCES}

1. Mills SA. Cerebral injury and cardiac operations. Ann Thorac Surg 1993;56:S86-91.

2. Clark RE. Cardiopulmonary bypass and thyroid hormone metabolism. Ann Thorac Surg 1993;56:S35-42.

3. Ragellar M, Quintel M, Bender HJ, Albrecht DM. Myxedema coma as a rare postoperative complication [German]. Anaesthesist 1993;42:179-83. 